ISSN: 0514-7336

DOI: http://dx.doi.org/10.14201/zephyrus2019835977

\title{
DINÁMICAS COMERCIALES ENTRE HISPANIA Y MAURETANIA CAESARIENSIS. ALGUNAS REFLEXIONES A PARTIR DE LA EVIDENCIA CERÁMICA (SS. I-V D. C.)
}

\section{Commercial dynamics between Hispania and Mauretania Caesariensis. Some considerations from pottery evidence ( $I^{s t}-V^{\text {th }}$ centuries $\left.A D\right)$}

\author{
Alejandro Quevedo SÁnchez
}

Dpto. de Prehistoria, Arqueología, H. ${ }^{a}$ Antigua, H. ${ }^{a}$ Medieval y CC y TT Historiográficas. Facultad de Letras-UMU. C/ Santo Cristo, 1. 30001 Murcia. Correo-e: alexquevedo@um.es. ID ORCID: 0000-0002-0645-4279

Recepción: 25/10/2018; Revisión: 14/3/2019; Aceptación: 17/04/2019

\begin{abstract}
Resumen: Durante la Antigüedad las dos orillas del Mediterráneo occidental, la Península Ibérica y el Magreb, compartieron un rico pasado común favorecido por su estrecha proximidad geográfica. Sin embargo, nuestro conocimiento sobre los intercambios entre ambos territorios es muy desigual. Mientras que en el "Círculo del Estrecho" la investigación arqueológica ha avanzado de manera exponencial en las últimas décadas, los datos para el sector oriental se basan aún principalmente en la documentación epigráfica y literaria. Esta aproximación, que pone en valor los vínculos de carácter sociopolítico, resulta insuficiente para el análisis del comercio: la información es poco precisa y no permite evaluar con exactitud el volumen de las transacciones efectuadas. El objetivo de este trabajo es estudiar la naturaleza e intensidad de las relaciones económicas entre las costas del norte de Argelia y las del Levante peninsular a partir de la evidencia cerámica. La elección de este material está motivada por su pervivencia en el registro arqueológico. En este artículo se plantea un análisis cualitativo y cuantitativo del material cerámico conservado, cruzando los datos más recientes con la reinterpretación de antiguos contextos ya publicados. Cronológicamente el estudio se extiende desde la anexión romana de Mauretania Caesariensis hasta la Antigüedad Tardía.
\end{abstract}

Palabras clave: Argelia; economía; comercio romano; cerámica romana; ánfora; Antigüedad Tardía.

Aвstract: During Antiquity the two shores of the western Mediterranean, the Iberian Peninsula and the Maghreb, shared a rich common past favoured by their close geographical proximity. However, our knowledge of the exchanges between the two territories is very uneven. While archaeological research in the "Circle of the Strait" has advanced exponentially in recent decades, data for the eastern sector are still based mainly on epigraphic and literary documentation. This approach, which highlights the value of socio-political links, is insufficient for trade analysis: the information is imprecise and does not allow the volume of transactions carried out to be accurately evaluated. The aim of this paper is to study the nature and intensity of the economic relations between the coasts of Northern Algeria and those of the peninsular east on the basis of pottery evidence. The selection of this material is motivated by its continuity in the archaeological record. In this paper I propose a qualitative and quantitative analysis of the preserved ceramic material, crossing the most recent data with the reinterpretation of old archaeological contexts already published. Chronologically, the study extends from the Roman annexation of Mauretania Caesariensis to Late Antiquity.

Key words: Algeria; economy; Roman trade; Roman pottery; amphora; Late Antiquity. 


\section{Introducción ${ }^{1}$}

En el estudio de los intercambios comerciales de época romana en el Mediterráneo occidental, un territorio brilla por la falta de datos: Argelia. Con la información disponible en la actualidad resulta difícil discernir cuál fue el papel de la Mauretania Caesariensis en el sistema económico del Imperio, incluida su aportación a la annona. Este desconocimiento deriva de un doble fenómeno. Por un lado, el hecho de que tradicionalmente la investigación haya prestado menos atención al estudio de los aspectos económicos, habiéndose inclinado por una arqueología centrada en los grandes monumentos y la epigrafía (Gsell, 1911; Lancel, 2003). Por el otro, la circunstancia de que algunos de los productos más célebres que exportó la provincia y cuya noticia nos ha llegado a través de fuentes tardías, como el grano, los tejidos o los esclavos (Expositio totius mundi et gentium, 60), pero también las maderas nobles o los animales salvajes, sean difícilmente identificables en el registro arqueológico.

Sin embargo, es posible profundizar en el estudio de las redes de intercambio a partir del análisis de una fuente abundante y apenas explotada en la región: la cerámica. El valor de este material como documento para la historia económica ha sido puesto

1 Este trabajo se enmarca dentro de los proyectos de investigación HispanialAfrica: modelos urbanos y relaciones de interdependencia entre las dos orillas del Mediterráneo occidental (ss. $I-V$ d. C.) del Plan Propio de la Univ. de Murcia y Nuevas metodologías para el estudio la economía del Sureste en época romana. Anforas: caracterización tipológico-arqueométrica y análisis orgánico de contenidos de la Fundac. Séneca-Agencia de Ciencia y Tecnología de la Región de Murcia. Asimismo, la contribución se ha realizado en el marco de los proyectos De municipia latina a oppida labentia: sobre la sostenibilidad económica e institucional del municipio de derecho latino en la Hispania romana (siglos II y III d. C.), referencia HAR2016-7485-P y Pictores et officinae per provincias. La circulación de modelos pictóricos urbanos y rurales por el sur de la Tarraconense y de la Lusitania desde una perspectiva integral, referencia HAR2016-74847-P, financiados ambos por el Ministerio de Economía y Competitividad. El autor actualmente es investigador contratado en la Univ. de Murcia e investigador asociado al Centre Camille Jullian (Aix-Marseille Univ., CNRs, MCC, CCJ, Aix-en-Provence, France). de relieve de manera incontestable en otras zonas del Magreb, y de manera señalada en el Africa proconsular (Hayes, 1972; Panella, 1993; Bonifay, 2004; Bonifay y Tchernia, 2012). No obstante, la costa argelina continúa siendo un importante vacío en lo que a producción cerámica y distribución se refiere; un vacío que se torna literalmente físico con solo observar algunos mapas (Reynolds, 2010: 161, mapa 2; Bonifay, 2016: figs. 125, 127 y 129). Con el fin de completar este desequilibrio en el presente trabajo se plantea un análisis de las producciones cerámicas y los contextos de consumo conocidos en el oeste mauritano, contrastados con otros datos procedentes de la orilla norte: el Levante de Hispania.

La elección del marco geográfico, que atañe principalmente a la franja costera, más densamente poblada y con los principales puertos (Yorke y Davidson, 1969: 8-17), está marcada por la existencia de unas relaciones históricas que se remontan a la época de los reinos independientes (Gozalbes, 1993; Bernard, 2018). Tras la división de las Mauretaniae y la anexión de la Caesariensis al Imperio Romano, a inicios del s. I d. C., estos vínculos se intensificarán, como se ha puesto de manifiesto en un reciente congreso ${ }^{2}$. El espacio argelino analizado corresponde al sector central de la antigua provincia ${ }^{3}$, situado entre el valle del Chlef y el límite oriental de la Gran Cabilia (Fig. 1). Es el territorio más cercano al e de la Península Ibérica y la distancia que lo separa del $\mathrm{N}$ de África se cubría en apenas tres días de navegación, existiendo rutas directas entre algunas de las principales ciudades como Carthago Nova -Cartagena- e Iol/Caesarea-Cherchel-, tal y como recuerda Plinio (Nat. Hist. 3,13). De hecho, esta

2 De una orilla a la otra: circulación e intercambios entre Mauritania Cesariense y el Sureste de Hispania. Antigüedad-Edad Media, organizado por la Escuela Española de Historia y Arqueología (A. Quevedo) y la Casa de Velázquez (T. Amraoui), en Roma en febrero de 2017, en curso de publicación.

3 En su momento de máxima extensión, en época severiana, la Mauretania Caesariensis alcanza los $700 \mathrm{~km}$ de longitud en su franja costera (penetrando unos 150-200 km en el interior del continente), si bien tras la reforma de Diocleciano en 303 d. C. su parte más oriental se escindirá, formando la Mauretania Sitifiensis (Laporte, 2011: 111-115). 


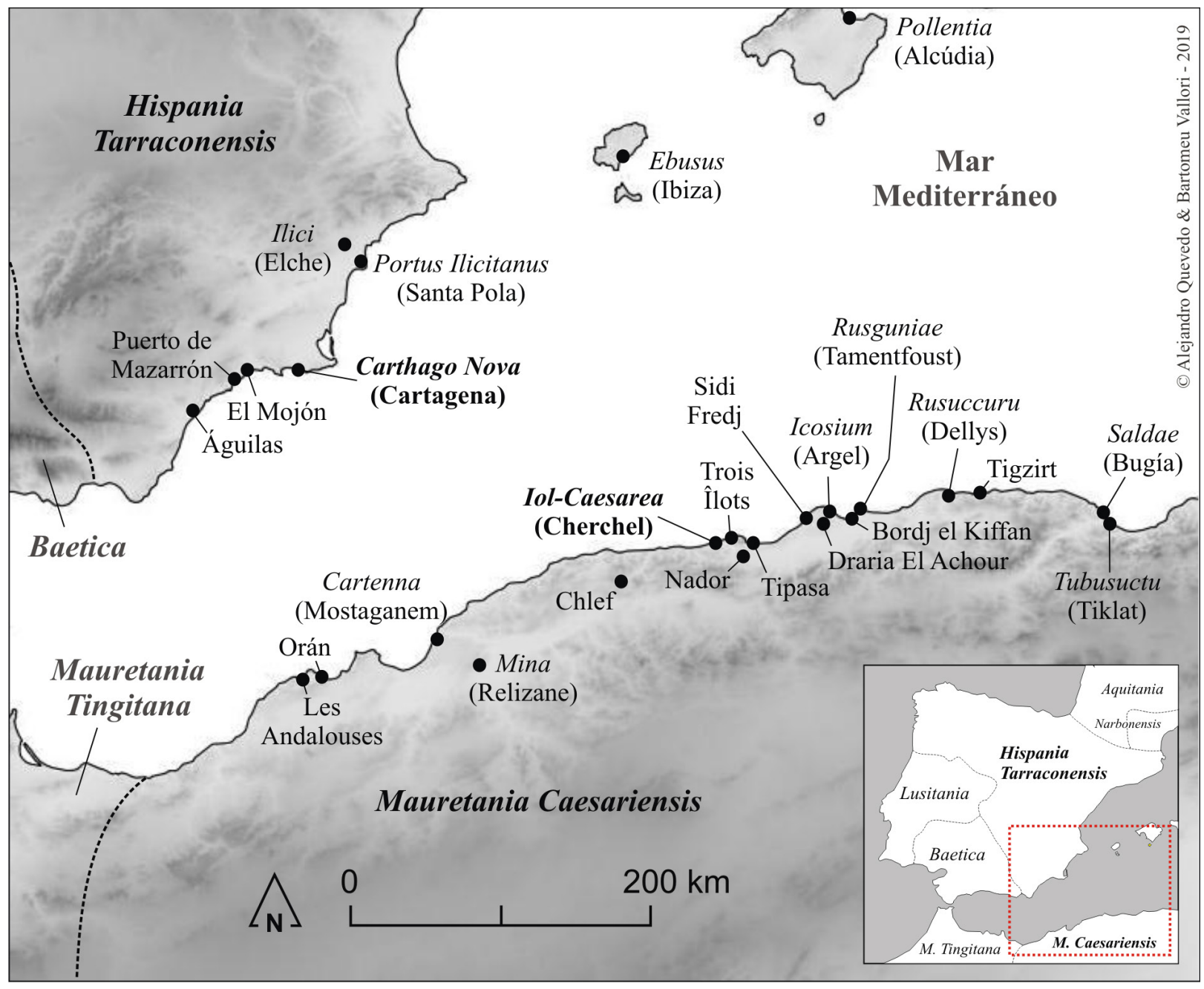

FIG. 1. Mapa del área de estudio con los principales yacimientos citados en el texto.

proximidad sugiere la existencia de intercambios y dinámicas comerciales específicas, como sucede en otras zonas cercanas entre sí y mejor conocidas, caso de la Baetica y la Mauretania Tingitana (Bernal et al., 2008) o de Túnez y Sicilia, para la que se ha planteado una relación similar a la del "Círculo del Estrecho” (Bonifay y Malfitana, 2016). Con el objetivo de aportar nuevos elementos de discusión se analizan distintas categorías cerámicas entre el Alto Imperio y época vándala -ánforas, cerámica fina, común, de cocina y lucernas-, incidiendo en aquellas producciones menos estudiadas. A la reinterpretación de la escasa información publicada se añaden diversas observaciones de campo realizadas por el autor.

\section{La producción cerámica en la Mauretania Caesariensis. Problemas de investigación}

El estudio de las producciones cerámicas en la Argelia romana está condicionado por una doble dificultad: la escasez de contextos cuantificados y de análisis arqueométricos. Buen ejemplo de ello es la ausencia de contribuciones en la serie de congresos trianuales del LRCW $^{4}$, iniciada en 2002, donde los datos presentados relativos al Magreb conciernen principalmente al actual Túnez (Bonifay y Treglia, 2010: 1033-1035).

4 Late Roman Coarse Wares. Cooking Wares and Amphorae in the Mediterranean: Archaeology and Archaeometry. 
El primero de los problemas citados es un reto mayor para la investigación, dado que gran parte del material conocido son hallazgos aislados o sin procedencia. Para la zona costera central de la provincia dos publicaciones emblemáticas constituyen una excepción: las excavaciones del castellum de Nador, cercano a Tipasa -más conocido por ser, en época tardía, la villa de M. Cincius Hilarianus (Anselmino et al., 1989)-, y las del foro de Cherchel (Benseddik y Potter, 1993), realizadas ambas en los años 70 del s. XX con metodología arqueológica. El resto de datos procede principalmente de necrópolis como las de Cherchel (Leveau, 1977, 1983)5, Draria-el-Achour (Camps, 1955), Rusguniae (Guéry, 1970), Argel (Le Glay, 1968) ${ }^{6}$ y Tipasa (Baradez, 1969; Lancel, 1970; Bouchenaki, 1975). Este último yacimiento, profusamente excavado, cuenta también con trabajos que recogen cerámicas halladas fuera del ámbito funerario (Baradez, 1961). A esto se suman antiguos fondos, como la colección Albert Pradel, formada por 631 objetos procedentes de las excavaciones realizadas en 1950 por este amateur de la arqueología en terrenos de su propiedad en Rélizane, la antigua Mina. Una parte de este material, fechado entre el s. I a. C. y el vi d. C., fue objeto en 2014 de una exposición en París ${ }^{7}$. Aun sin procedencia estratigráfica se trata de uno de los lotes más importantes de la interesante pero también poco conocida región que se extiende entre Mostaganem y Orán. En el territorio de esta última los contactos con la otra orilla están

5 Ciudad a la que cabe añadir un informe inédito sobre la intervención en los terrenos de la llamada "villa Marcadal" por Abbaci, A. y Souq, F. (2014): Diagnostic archéologique du terrain Marcadal, Cherchell (Algérie). Archéologie préventive et patrimoine "sauver Cherchell'.

6 Quevedo, A.: "La nécropole septentrionale d'Icosium (Alger). Évolution d'un espace périurbain antique d'après l'étude du mobilier funéraire". En Benseddik, N. (ed.): Ikosim/Icosium, Bulletin d'Archéologie Algérienne, Suppl., en prensa.

De Carthage (Tunisie) à Mina (Algérie): Les collections Gauckler et Pradel: un éclairage nouveau sur une carrière scientifique et sur un site archéologique, realizada en el Musée d'Archéologie Nationale et Domaine National de Saint-Germain-en-Laye entre el 14 de febrero y el 28 de abril de 2014 y comisariada por el conservador en jefe Ch. Landes (2014: 16-17). atestiguados desde la Edad del Hierro, como ilustra la profusión de cerámica ibérica del Sureste, con algunos hallazgos polémicos como el de la necrópolis de Les Andalouses (Kouici, 2002: 281-283).

En fechas recientes la intervención más destacada es la operación arqueológica argelino-francesa de Sahet echouhada -la plaza de los Mártires, Argel-, desarrollada gracias una colaboración entre el Centre National de Recherche en Archéologie -CNRA, Argelia- y el Institut National de Recherches Archéologiques Préventives -INRAP, France-. Entre 2013 y 2017 esta excavación de $8000 \mathrm{~m}^{2}$ a los pies de la Casbah, motivada por la ampliación de la línea de metro y por el grado de protección del que goza la zona, Patrimonio Mundial de la unesco, ha hecho emerger diferentes fases de ocupación que se extienden desde época antigua al s. xx. El horizonte romano, en curso de estudio y publicación, abarca desde los últimos siglos de la República hasta la Antigüedad Tardía ${ }^{8}$. Asimismo, no cabe olvidar algunos trabajos de prospección, como los 39 yacimientos que identificara en el territorio de Cherchel Ph. Leveau (1984: 449-464), los numerosos puntos documentados en la costa de Argel (Salama, 2006) o los más recientes estudios realizados en el valle del Chlef por el equipo de B. Boussadia?.

La segunda cuestión, relativa a los análisis de pastas, no es menos importante, puesto que afecta

8 Miembro de la misión y responsable del estudio y catalogación de los contextos cerámicos romanos, entre 2014 y 2016 realicé seis meses de trabajo sobre el terreno. Esta tarea se completó con la revisión de otros contextos de Argel, como el de la necrópolis de Bab-el-Oued, excavada a finales del s. XIx y conservada en el Musée National des Antiquités d'Alger, así como repetidas visitas a otros museos y yacimientos, en especial a Cherchel y Tipasa; Quevedo, $o p$. cit. n. 6. Una parte de los datos que se citan en estas páginas tienen que ver con esta experiencia y, a la espera de futuras publicaciones en colaboración con los colegas argelinos, se basan en observaciones personales.

9 Boussadia, B.; Diloli, J.; Amokrane, N. y Bea, D.: "La côte de la basse vallée de Chlef. Algérie occidentale, durant l'antiquité: exemples de pérennité des relations avec le littoral hispanique". En Quevedo, A. y Amraoui, T. (eds.): D'une rive à l'autre. Circulations et échanges entre la Maurétanie césarienne et le sud-est de l'Hispanie. Oxford: Archaeopress Archaeology, en prensa. 
directamente a la identificación de las diferentes categorías cerámicas y, en especial, a los productos locales destinados a la exportación por vía marítima como las ánforas. Tanto las estructuras de producción en el territorio estudiado - para un inventario reciente, vid. Amraoui, 2017, con bibliografíacomo los contenedores de transporte que pueden considerarse mauritanos son muy escasos (Panella, 2001: 207). La única forma que no admite dudas en cuanto a su origen es la Dressel 30/Keay IA, que se produjo tanto en Tubusuctu-Tiklat- como en Saldae-Bugía-, como se desprende de sus sellos: (ex) $P$ (rovinciae) M(auritaniae) C(aesariensis), SAL(dae) / (de) OF(ficinae) PLOTIOR(um) y EXPROV(incia) / MA$V R$ (etania) CAES(ariensis) TVBVS(vctv) (Fig. 2, n. ${ }^{\circ}$ 1), de los que se conocen hasta diez versiones (Laporte, 1976-1978: 138, fig. 6). La referencia a la provincia y a las mencionadas ciudades -situadas a escasos 4 $\mathrm{km}$, en la desembocadura del río Soummam- hace pensar en la existencia de un control directo de las autoridades urbanas sobre la producción (Laporte, 2010). Sin embargo, se ha constatado la fabricación de tipos muy similares en otros puntos del Magreb, como el África proconsular (Bonifay, 2016: $517-$ 518). Esto obliga a extremar las precauciones a la hora de la identificación ya que los únicos fragmentos que pueden asociarse de manera inequívoca a la Cesariense son aquellos sellados o cuya pasta ha sido sometida a análisis arqueométricos ${ }^{10}$. A la lista de contenedores supuestamente mauritanos pero que no pueden adscribirse con seguridad a esta región cabría sumar los tipos Keay IB, producido entre el s. IV y la primera mitad del s. v y acaso la forma Agora K 109, que parece una variante estilizada de la Dressel 30 (Fig. 2, n. ${ }^{\circ}$ 2). Otro envase considerado oriundo de este territorio, la forma "statio 48 de la plaza de las Corporaciones", que figura en la mencionada plaza de Ostia Antica, ha sido recientemente reinterpretado como un posible contenedor del

10 Laporte (2010: 605) observa ... "Nombre de signalements 'd'amphores de Césarienne' sont fortement suspects et mériteraient d'être vérifiés un à un. Les listes, parfois données sur des bases uniquement bibliographiques, sortiraient sans aucun doute notablement réduites d'un réexamen des objets eux-mêmes"...
África proconsular. Presenta un sello con las letras $M C$ separadas por una palmera, que en un primer momento se relacionaron con Caesarea de Mauretania. Ahora se plantea que su origen radique en las islas tunecinas de los Querquenes (Kerkennah), donde también son características las palmeras, que se utilizan para construir empalizadas para la pesca, leyendo el sello como M(unicipium) C(ercina) (?) (Bonifay, 2016: 513). Por último, no cabe descartar que tipos como la Africana III se produjeran también en Argelia, como deja intuir el pecio de la Pointe de la Luque в de Marsella, con un cargamento que incluía lucernas del área de Tipasa-Cherchel (Dovis-Vicente, 2001; Bonifay, 2004: 123-125). Para otros envases distribuidos esencialmente en Hispania, también se ha sugerido un origen argelino, como Keay 3в similis y Keay 24 (Keay, 1984: 179-184; Bonifay, 2004: 457). En cualquier caso es evidente que la sorprendente escasez de ánforas propias en el fértil litoral mauritano no puede responder más que a un vacío de la investigación.

La ausencia de análisis arqueométricos impide a su vez caracterizar otras categorías cerámicas como la vajilla fina, a excepción de aquellas selladas -terra sigillata itálica, gálica e hispánica- importadas a Mauretania (Guéry, 1979, 1987, 1992). Recientemente se ha planteado la existencia de una producción de sigillata en Argelia con decoración en forma de pelta, de pasta clara y compacta, con un engobe anaranjado y mate cuyos fragmentos se han encontrado en Tipasa y Tigzirt (Bonifay, 2013: 541, n. 47). Asimismo, para algunos tipos tardíos de sigillata africana como las formas Hayes 87 в у с, muy abundantes en Alicante, se ha sugerido igualmente un origen argelino (Reynolds, 1995: 11). Como se explica en líneas inferiores, también se desarrolló una cerámica de cocina regional, documentada en época tardía, y que imita formas típicas de la Proconsular. Por último, en lo que respecta a las lucernas, dos son los tipos principales producidos en territorio argelino, probablemente en Tipasa, como se deduce de su elevada concentración en la ciudad y su entorno: las formas Bussière E IV y E V (Bussière, 2000: 120-126). Ambas se caracterizan por no presentar engobe, siendo su pasta de color beige, muy 
depurada. La primera, también llamada "lucerna de canal curvo" (Fig. 2, n. ${ }^{\circ} 3$ ), presenta en ocasiones sobre la margo la leyenda en relieve LVCERNA COLATAS AB ASSE que haría alusión al taller de Assenes. Se trata de tipos que alcanzaron una cierta difusión en el Mediterráneo occidental entre los ss. Iv y v d. C., en especial en las costas hispanas -Cartagena, Alicante, Elche y Pollentia-.
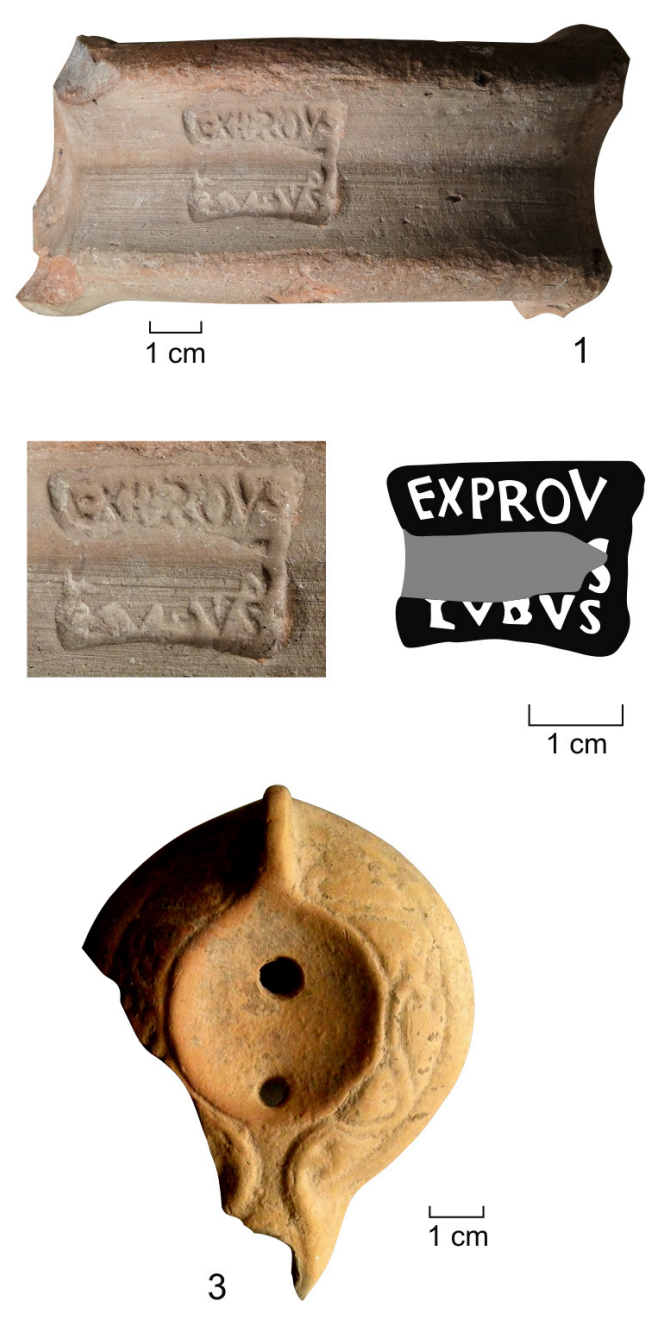

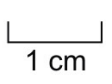

1

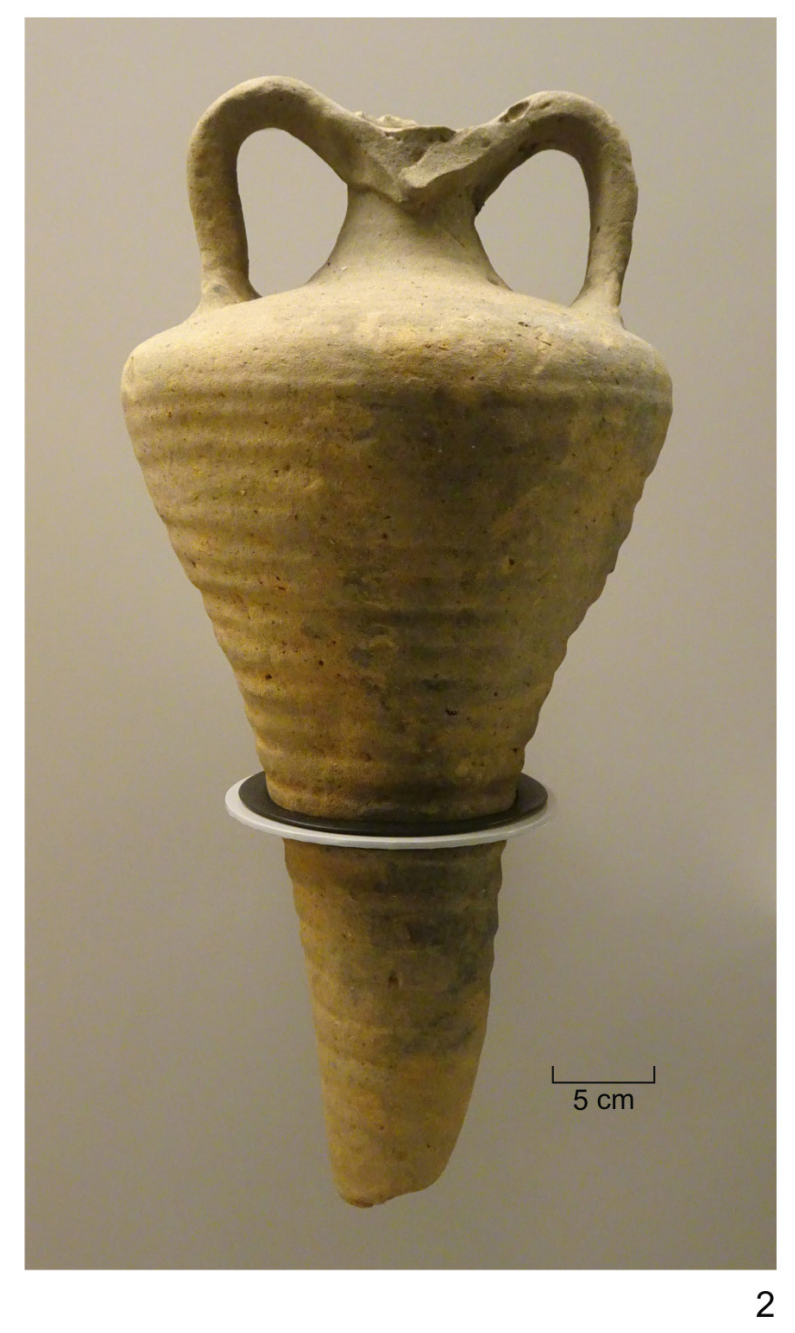

FIG. 2. Producciones mauritanas procedentes de contextos de consumo del Sureste hispano: 1) ánfora Dressel 30/Keay IA con sello ex prov(incia)/Ma(v)r(etania) CaEs(ariensis) Tvbvs(vctv) (Ilici, Museo Arqueológico La Alcúdia de Elche, cortesía A. Ronda, dibujo A. Quevedo); 2) ánfora Ágora 109 ¿evolución tipo Dressel 30? (Museo Arqueológico de Murcia, sin procedencia); 3) lucerna de canal curvo de posible producción tipasitana hallada en Cartagena (Quevedo, 2015: fig. 163.5).

\section{Intercambios entre el o de Mauretania Caesariensis y el SE hispano durante el Alto Imperio (ss. I-III d. C.)}

La provincia de Mauretania Caesariensis entra oficialmente en la órbita de Roma tras su anexión bajo el mandato de Claudio, en 40 d. C. A partir de ese momento Hispania parece ocupar un papel privilegiado en las relaciones comerciales con este territorio, que también mantenía fuertes contactos históricos con Túnez e Italia. Las excavaciones de la villa rustica de Nador muestran un elevado porcentaje 
de ánforas procedentes de esta región en los contextos asociados a la primera fase del establecimiento, fechada entre el segundo cuarto del s. I y el in d. C. (Manacorda, 1989: 204-205). Las ánforas de la Baetica $-84 \%$ - son las mejor representadas (Fig. 3, n. $\left.{ }^{\circ} 1\right)^{11}$, en especial las Dressel 7-11 de salazones de la bahía de Cádiz -57\%- que también son las más abundantes en el foro de Cherchel (Benseddik y Potter, 1993: 295) y las Dressel 20 para aceite del valle del Guadalquivir -25\%- ${ }^{12}$. Asimismo, completan el lote algunos ejemplares béticos del tipo Beltrán $2 \mathrm{~B}^{13}$ y Haltern 70 , al que se suma un reducido porcentaje de Dressel 2-4 de la Tarraconense $-8 \%-{ }^{14}$. El grupo hispano es seguido de lejos por las ánforas itálicas $-2 \%$, tipos Dressel 2-4- y africanas $-2 \%$, tipos Africana I y II-. Porcentajes similares de estas producciones, aunque en mayor cantidad, han sido identificados en Icosium -Argel- en niveles de esta misma cronología, donde se detecta igualmente una importante cantidad de ánforas vinarias de Ibiza. Dichos contenedores habían sido ya documentados

11 Gráfico elaborado a partir de los datos publicados por Manacorda (1989: 183-185, tabla 13). Con el objetivo de aplicar el Número Mínimo de Individuos -NMI- y ajustar las cifras existentes he divido entre dos el número de asas y eliminado los fragmentos informes y otros elementos, como las tapaderas en el caso de las Dressel 20 -a título de ejemplo a los 130 fragmentos de Dressel 7-11 he ańadido 68 asas, la mitad de las 136 contabilizadas, lo que eleva el total de ítems de esta ánfora bética a 198-.

12 Los fondos del Musée National des Antiquités et des Arts Islamiques d'Alger atesoran un importante conjunto inédito de asas de Dressel 20 selladas halladas en territorio argelino, desgraciadamente sin procedencia exacta. Vaya mi más sincero agradecimiento tanto a las directoras de la institución durante mis visitas, $\mathrm{H}$. Cherid y, a partir de 2016, H. Boukhames, así como a la jefa del Dpto. de Antigüedades, A. Soltani, y, en especial, a Nadia y al resto del equipo de conservadores del museo, por sus atenciones a la hora de permitirme consultar el material.

13 Un posible pecio localizado en Sidi Fredj contenía un cargamento de estas ánforas (Salama, 2006: 533-534).

14 Otra Dressel 2-4 -quizás también tarraconensefue reutilizada en una tumba en la necrópolis occidental de Cherchel junto a un tipo Pascual 1 (Leveau, 1983: 156, fig. $81)$. Un sello procedente de Cherchel puede asociarse igualmente a estas producciones (Salama, 2006: 545), también presentes en Sahet echouhada, Argel. en Gouraya y Tipasa (Ramon, 2008: 78, fig. 3). Su ausencia en las publicaciones se debe únicamente a un problema de identificación, como demuestran los fragmentos erróneamente clasificados de las excavaciones de Nador (Manacorda, 1989: 182, fig. 42 , n. ${ }^{\circ} 231$ ) -clasificado como Keay 72 , se trata en realidad del tipo ebusitano $\mathrm{PE}-25$, fechado entre finales del s. II e inicios del s. iII d. C. según Ramon, 2006: 259-263, fig. 8 y 9-. Lo mismo sucede en Cherchel, donde el numeroso grupo de las thick round handles (Benseddik y Potter, 1993: 295) ha de asociarse en realidad a ánforas de Ibiza (Fig. 3,

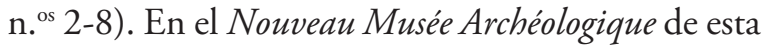
última localidad se hallan expuestos varios ejemplares completos del tipo PE-17.

A partir de la segunda mitad del s. II las ánforas africanas acrecentarán su presencia en detrimento de los contenedores hispánicos, siguiendo un esquema bien conocido - para el caso de Ostia vid. Rizzo, 2014: 398-399 y 410, tab. 6- que arranca con la llegada de los tipos Africana I y II, de las que se documentan hallazgos aislados en Rusguniae y Sidi Ferruch (Salama, 2006: 541-542, figs. 20-21), así como en Tipasa, Cherchel y Nador (Manacorda, 1989: 176). Conviene asimismo reseñar la escasa presencia de ánforas Dressel 30/Keay IA, a excepción de una concentración "considerable" (sic) de ejemplares en Rusguniae (Salama, 2006: 541-552), acaso un posible pecio (?), junto a un ejemplar aislado citado en las mismas páginas y procedente en Bordj el Kiffan. Asimismo, estos contenedores se encuentran casi ausentes en las estratigrafías de Sahet echouhada, lo que parece subrayar su carácter exportador fuera del territorio mauritano, encontrándose en gran parte del Mediterráneo, pasando por Egipto, donde pudieron ser reutilizadas, y llegando incluso hasta Sudán (Laporte, 2010: 618621). En Hispania están especialmente documentadas en Elche -Ilici-, donde perduran más allá del s. III d. C. (Tendero y Ronda, 2014: 281).

En lo que respecta a la vajilla de mesa, la producción porcentualmente mejor representada es la terra sigillata africana-TSA-, seguida por las sigillatas galas -TSG-, las itálicas -TSI- y, en pequeñas cantidades, las hispánicas -TSH-. En orden cronológico, en 


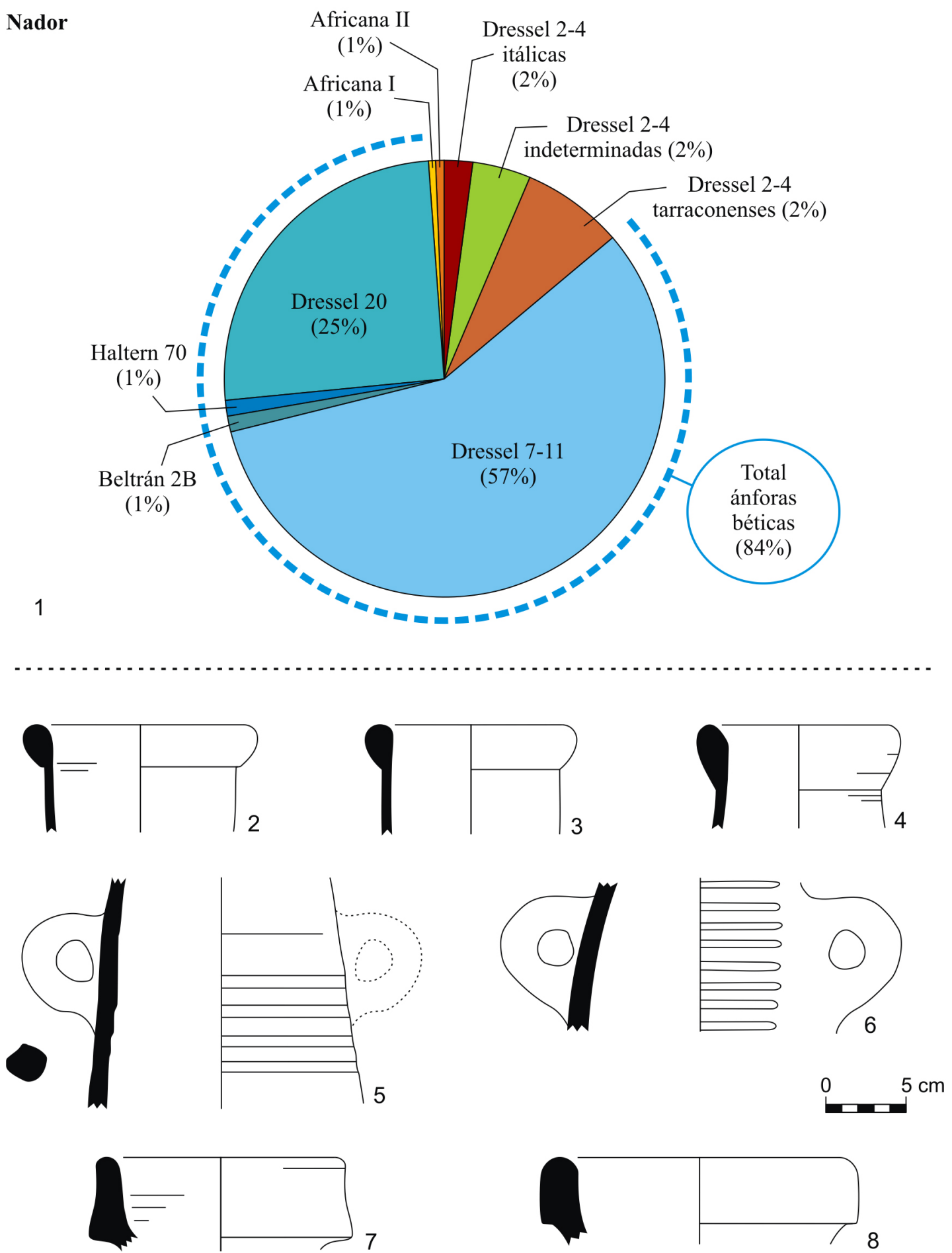

FIG. 3. Ánforas hispanas procedentes de contextos argelinos: 1) predominio de contenedores béticos en la villa de Nador (a partir de Manacorda, 1989: 183-185, tab. 13); 2) ánforas ebusitanas procedentes del foro de Cherchel interpretadas erróneamente en la época: 2-6: PE-17, 7-8: PE-25 (a partir de Benseddik y Potter, 1993; 2 = fig. 109.570, 3 = fig. 107.542, 4 y $6=$ fig. 75 'Fusiform type', $5=$ fig. 83.64, $7=$ fig. 106.57, $8=$ fig. 75 Dr. 6/Lamb II). 
los contextos de la primera mitad del s. I d. C. se documentan las formas clásicas de TSI y TSG, de las que Caesarea y las villae de su ager, que se desarrollan en este momento, ofrecen un claro ejemplo. Entre los tipos documentados en este territorio destacan, en TSI, las formas Conspectus 4.4, 14.1-2, 15.1, 20.3$4,22.1-3,23,27.1,31,33,34,50 \ldots$ y en TSG las Dragendorff 15/18, 16, 17, 18/31, 24-25, 27, 29, 37 y Ritterling 8 (Leveau, 1984: 450-452, fig. 242). La situación se repite en Nador (Manacorda, 1989: 129-132) y en otras necrópolis como las de la propia Cherchel, Tipasa y Argel $^{15}$. A partir de época flavia hace su irrupción la TSA A, que predominará durante los siglos siguientes, como muestran las prospecciones realizadas alrededor de Cherchel, donde esta producción representa más del $80 \%$ de los fragmentos recogidos con, entre otros, formas clásicas como Hayes 3B, 3c, 8A, 8B, 9, 10 et 14/17 (Leveau, 1984: 452-454, fig. 243). En yacimientos como Tipasa se encuentran formas menos frecuentes como Hayes 10, así como un gran repertorio de formas cerradas (Lancel, 1970: 234-237, figs. 76 y 80). Desde finales del s. II d. C. se documentan las formas más tardías de la TSA A, así como ejemplares en TSA A/D, caso de los tipos Hayes 27/32 y 31 (Leveau, 1984: 452-454, fig. 243).

En cuanto a la TSH, propia de este horizonte, el plato Dragendorff 15/17 parece la forma casi exclusiva (Guéry, 1979: 31-37; Leveau, 1983: 144, fig. 70 м127; Dorbane, 1998: 41-42), si bien se documentan otros tipos como un bol Dragendorff 37 en Cherchel (Benseddik y Potter, 1993: 340, fig. 99.376).

Por último, en esta cronología y adentrándose ya en el s. III, destaca el vaso de paredes finas tipo Cartagena (Fig. 4, n. ${ }^{\text {os }} 1-2$ ), cuya producción se asocia a la región de Ilici-Carthago Nova (Quevedo, 2015: 52-53, fig. 28). Algunos fragmentos se hallaron en Sahet echouhada y se expone un ejemplar completo en el Nouveau Musée Archéologique de Cherchel. En Nador cabría asociar este tipo a un fragmento que "... non è parso identificabile ad alcune delle forme note..." (Manacorda, 1989: 132, fig. 27.9) y en Tipasa, el ejemplar

15 Quevedo, op. cit. n. 6. expuesto en una vitrina del museo (Fig. 4, n. ${ }^{\circ}$ 3) es muy probablemente el publicado por Bouchenaki (1975: fig. 100 M98bis).

Junto a las mencionadas producciones se encuentran las formas africanas de cocina clásicas, procedentes del África proconsular: las cazuelas Hayes 23 y Hayes 197, así como la tapadera Hayes 196, todas muy abundantes en especial en la necrópolis de Matarès en Tipasa (Bouchenaki, 1975) y en las necrópolis occidentales de Cherchel (Leveau, 1983). También se registran otros tipos culinarios africanos como Ostia III, 269 (Bouchenaki, 1975: fig. 66.M107) o la olla de cuerpo globular Hayes 200 (Lancel, 1970: 247-251, fig. 94.2), empleada como urna cineraria y frecuente también en las costas del Levante hispano. Cabe señalar la ausencia casi total en las publicaciones de producciones locales de cocina de esta época. No analizaré aquí las lucernas, que ya han sido objeto de trabajos monográficos (Bussière, 2000, 2007).

En lo que respecta a las producciones comunes merece especial atención, por lo que presentan de novedoso, un grupo recientemente denominado “cerámicas de pasta blanca'16. La definición de céramiques à pâte blanche- $\mathrm{CPB}-$ surge durante los trabajos de inventario de Sahet echouhada, donde esta producción es muy abundante desde finales del s. I a. C. Se trata de unas piezas de pasta blanquecino-amarillenta, que en ocasiones adquiere tonalidades beige e incluso rosadas en su sección. Se caracterizan por presentar pequeños desgrasantes arenosos de entre 1-3 mm, así como mica-esquistos e inclusiones de cal ligeramente más grandes, que confieren un aspecto rugoso a su superficie, que en ningún caso lleva engobe. Cabe señalar un cierto parecido con las cada vez mejor conocidas producciones de Málaga (Corrales et al., 2011: 42, fig. 12). La cronología de estas cerámicas parece arrancar en los últimos siglos de la República (vid. dos ejemplares de Tipasa fechados en este momento cuya descripción parece corresponder a la misma producción; Lancel, 1968: 132-133, figs. 105 y 108) y se prolonga hasta la Antigüedad Tardía, un amplio arco cronológico a lo largo del cual evoluciona

16 Quevedo,op. cit. n. 6. 


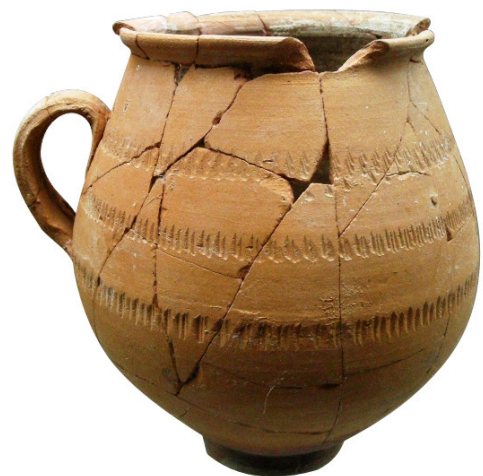

1

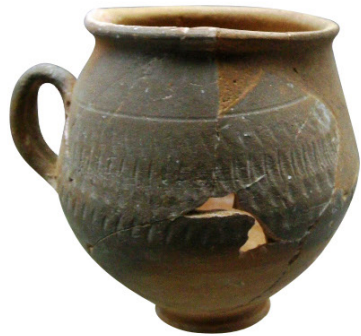

2

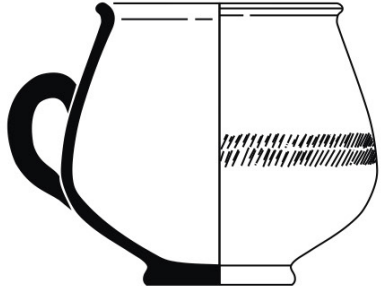

3

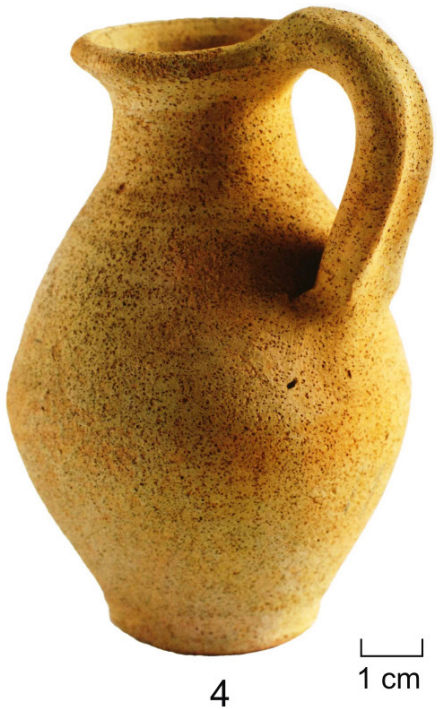

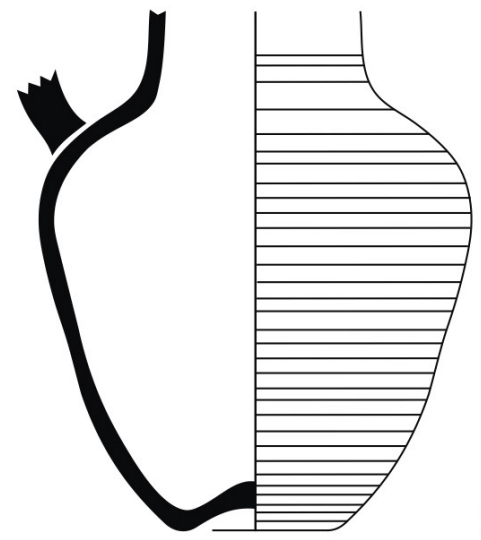

5

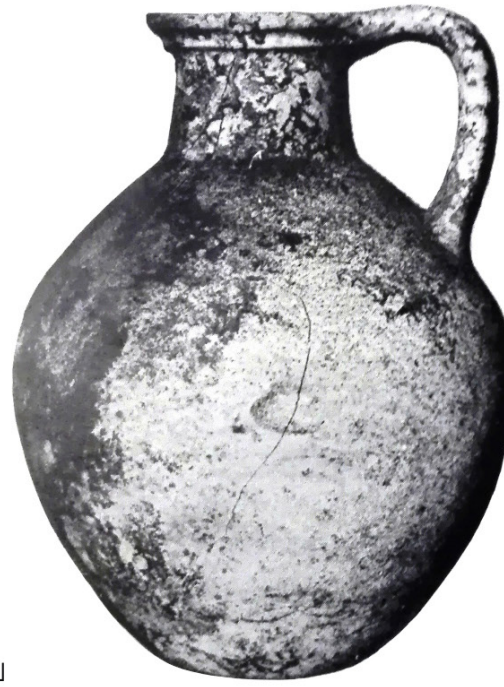

6

FIG. 4. 1-3) Tazas de paredes finas tipo Cartagena halladas tanto en el SE hispano (1 y 2 = Quevedo, 2015: 52, fig. 28.1-2), como en la costa argelina (3 = Tipasa, Bouchenaki: 1975, fig. 100.M98bis); 4-6) cerámica de pasta blanca (CPB) $(4=$ jarrita de la necrópolis de Bab-el-Oued, Argel; según Belacheheb, 2007: 103) (5-6 = grandes jarras tardías con fondo umbilicado de Tipasa; según Bouchenaki, 1975: fig. 105.12 y Anselmino et al., 1989: tav. XXVI, 1).

el repertorio tipológico. En época imperial este se compone básicamente de jarras. Destacan pequeñas jarritas de fondo plano (Fig. 4, n.o 4), muy abundantes en necrópolis como las de Tipasa (Baradez, 1969: 87, fig 3.7; 96, figs. 7.32, 7.31.30.49, 7.28, 7.36; p. 107, fig. 10.38) y Argel (Le Glay, 1968: 33, figs. 19 y 20). También hay ejemplares de servicio de mesa que imitan prototipos metálicos ${ }^{17} \mathrm{y}$ jarras de mayor tamańo, acaso para almacenaje o transporte

17 Quevedo, op. cit. n. 6. de líquidos - ¿agua?-, a menudo con el cuerpo estriado y caracterizadas por un asa (Fig. 4, n. ${ }^{\text {os }} 5-6$ ). Estas últimas abundan en Nador (Manacorda, 1989: 162, fig. 35.141-149), Tipasa (Lancel, 1970: 251, fig. 95) y Cherchel, donde se conserva un ejemplar completo expuesto en el Nouveau Musée Archéologique. Una de las características principales de la СРв es la unión del asa, que se produce siempre en el interior del borde, siguiendo una tradición que se remonta a época púnica. Se trata de formas 
muy abundantes para las que podría sugerirse una producción en alguno de los centros de la región -acaso Icosium, debido a los importantes porcentajes de estas piezas hallas en Sahet echouhada-.

Por último, entre las formas de cerámica común cabe destacar la jarra africana tipo Bonifay 50 , fechada entre los ss. II-III d. C. (Bonifay, 2004: 285), producida también en una pasta blanquecino-amarillenta acaso más depurada y con algunas inclusiones ocres. Su significativa presencia en Cherchel (Leveau, 1983), en cuyo museo se exponen numerosos ejemplares, lleva a pensar si quizás no se trata de un producto mauritano o producido también en este territorio y no solo en el África proconsular.

\section{Producción cerámica y comercio en Mauretania Caesariensis durante la Antigüedad Tardía (ss. IV-v d. C.)}

El horizonte material entre los Severos y los inicios de la Antigüedad Tardía en la región costera señalada se caracteriza por la ausencia de documentación ${ }^{18}$, también epigráfica, a pesar de ser paradójicamente uno de los mayores momentos de expansión constructiva, al menos en lo que a edilicia pública se refiere (Mansouri, 2002: 1386 y 1395). En cuanto al período sucesivo, sería especialmente interesante revisar material cerámico de varios contextos, en su mayoría de naturaleza funeraria, ricos en hallazgos numismáticos que van de Diocleciano a la segunda mitad del s. IV tanto en Tipasa (Lancel, 1970), como en Rusguniae (Camps, 1955) y Cherchel (Leveau, 1999: 108).

La falta de contextos cuantificables en época tardía dificulta la comprensión de las relaciones con la Península Ibérica, en especial en lo relativo a las ánforas. Aunque se identifican algunas importaciones béticas (Dressel 23) e ibicencas (Bonifay, 2013: 532), el escenario resulta muy cambiante por la

18 En Nador, aunque el grueso de las producciones cerámicas encontradas pertenece a la fundación del establecimiento agrícola -época de Claudio- y las décadas sucesivas, algunos materiales permitirían prolongar su ocupación en el tiempo hasta el s. III d. C. (Manacorda, 1989: 204-205). aparición de productos hispanos que pueden confundirse con ánforas lusitanas (tipos Almagro 50, 51a-b y 51c), lo que obligaría a revisar en detalle el material publicado. El aspecto más interesante a reseñar es la presencia en suelo argelino de producciones típicas de la costa de Carthago Nova, tanto de los talleres de Águilas como de los de la bahía de Mazarrón, en especial del alfar de El Mojón. Estas producciones se caracterizan por su pasta, de color beige y rica en inclusiones plateadas ${ }^{19}$, y por presentar en el cuello una serie de incisiones (Berrocal, 2012). Entre los tipos más habituales destacan el ánfora Mojón I, una imitación del tipo africano Keay 25 con una variante pequeña, Mojón IA, y otra de mayores dimensiones, Mojón Iв (Fig. 5, n. ${ }^{\circ}$ 1), así como pequeños spatheia, con y sin asas. Se trata de formas vinculadas al mundo de las salazones y las salsas de pescado, como se ha planteado para las ánforas de Águilas ${ }^{20}$. Consideradas inicialmente como una producción destinada a un comercio regional, el hallazgo de algunos ejemplares en África proconsular y Tripolitania (Bonifay, 2013: 532), y más recientemente en contextos tardíos de Ostia Antica ${ }^{21}$, está permitiendo redimensionar su impacto en las redes económicas de época tardía ${ }^{22}$. En Argelia B.

19 Aunque se ha establecido una división de los diversos talleres a partir de observaciones macroscópicas (Berrocal, 2012), las similitudes entre unos y otros, derivadas del uso de arcillas de naturaleza similar, ha obligado a la realización de análisis arqueométricos (A. Quevedo, en preparación).

20 Quevedo, A.; Sternberg, M. y Hernández García, J. D.: "The fish-salting production center of Águilas: content analysis on Late Roman Amphorae". En Bernal, D. (ed.): International Interactive Conference. Roman Amphora Contents. Reflecting on Maritime trade on food stuffs in Antiquity. RLAMP, Roman and Late Antique Mediterranean Pottery. Oxford: Archaeopress, en prensa.

${ }^{21}$ Contino, A. y Quevedo, A.: "Un contesto tardoantico dai c.d. magazzini traianei a Portus (Fiumicino)". En LCRW 6. Proceedings 6th International Conference on Late Roman Coarse Wares, Cooking wares, and Amphorae in the Mediterranean. Archaeology and Archaeometry (Agrigento, 2017). Oxford, en prensa.

22 Quevedo, A.: "Nuevos datos sobre producción, tipología y difusión de las ánforas de la región de Carthago Nova". En Ex Baetica Amphorare II. 20 años después. Actas del Congreso Internacional (Sevilla, 2018), en preparación. 

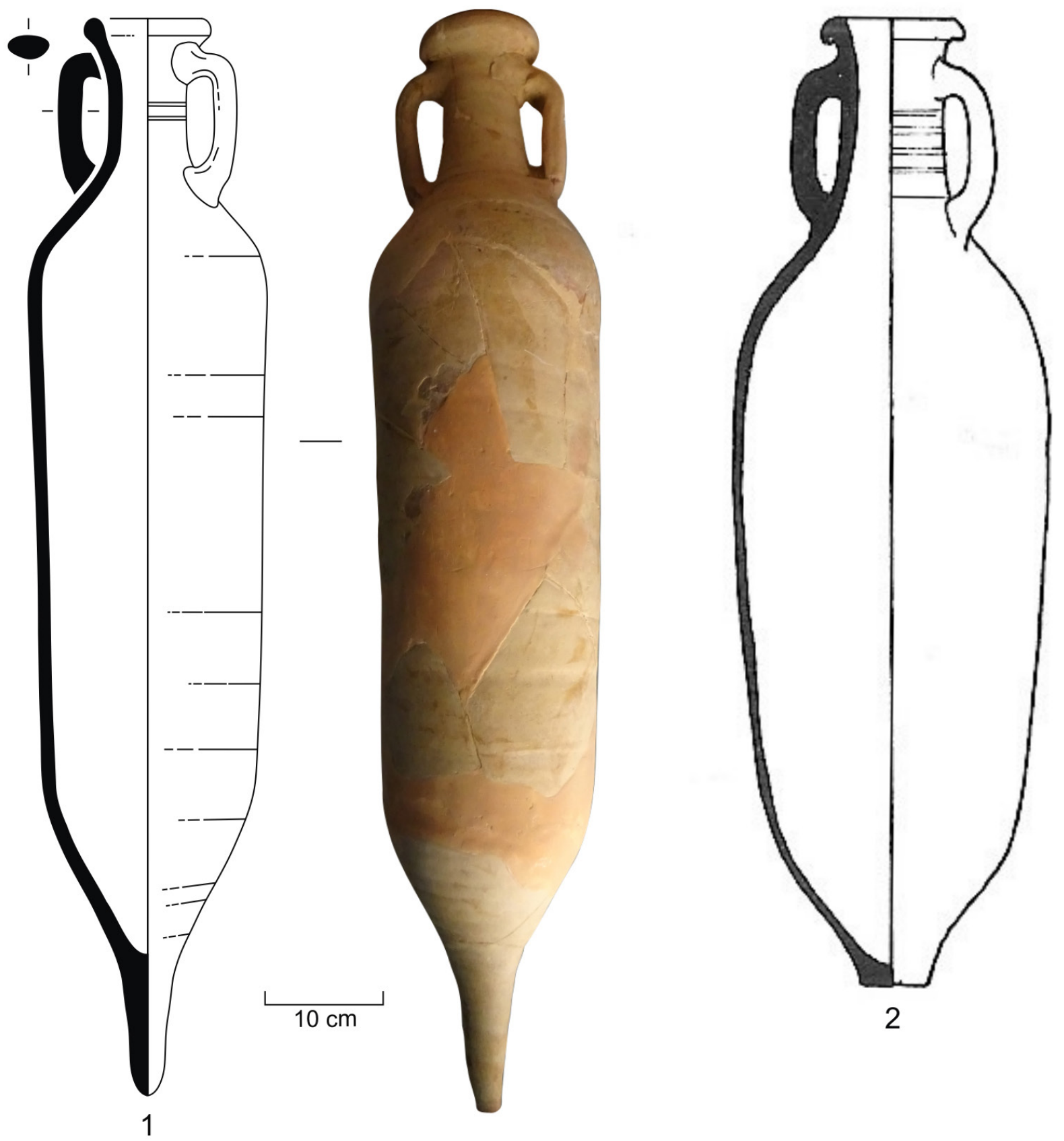

FIG. 5. Ánforas tardias de la costa de Cartagena imitación del tipo africano Keay 25 caracterizadas por su pasta micácea y la presencia de incisiones en el cuello: 1) Mojón IB, Águilas (cortesía de J. D. Hernández; dibujo: A. Quevedo); 2) Mojón IB, Tipasa (Bouchenaki, 1975: 103-108).

Boussadia $^{23}$ ha documentado diversos spatheia de estas características cerca de la desembocadura del Chlef, mientras que en Tipasa las incisiones en el

23 Boussadia, op. cit. n. 9. cuello de una Keay 25 publicada por Bouchenaki (1975: fig. 103.8,) permiten identificarla como una Mojón Iв (Fig. 5, n. 2).

Ante la falta de datos arqueométricos y estructuras de producción conviene ser especialmente prudente. 
Nada impide pensar que en la costa argelina (con una geología muy similar a la del Sureste peninsular) se produjeran también envases para salazones - ¿incluyendo formas de inspiración africana como sucede en el entorno de Cartagena?-. Esta hipótesis se apoya en la existencia de toda una serie de cetariae a las que por el momento no se vincula ningún tipo de contenedor cerámico, como las de Portus Magnus -Bethioua-, Cartili, Gouraya, Cherchel y su entorno -Cap Tizirine, Trois Îlots- ${ }^{24}$, Rusucuru -Dellys- o Tipasa, de carácter urbano. Estas últimas quizás sean las mejor conocidas y las únicas para las que es posible proponer una cronología aproximada, que no sería anterior a inicios del s. III d. C. (Amraoui, 2014).

En cualquier caso, a partir de época tardía los contextos del sector occidental de la Mauretania Caesariensis están marcados por un boom de cerámicas comunes y de cocina de producción propia. Buen ejemplo de ello es la excavación del llamado 'pozo del barrio de La Marina de Argel', de hasta $20 \mathrm{~m}$ de profundidad, del que por desgracia no se conservan materiales y donde la cerámica mayoritaria en este momento es la poterie romaine courante (Le Glay, 1968: 14-15, fig. 5). En las páginas que siguen se incide en este tipo de vajilla, quedando al margen la cerámica fina de importación, donde predominan las producciones del África proconsular -en especial talleres de El Mahrine y Oudhna (Bonifay, 2013)-, y las lucernas, pues las colecciones argelinas han sido objeto de un doble estudio monográfico en el que se incluyen los citados tipos locales Bussière E IV y E v (Bussière, 2000, 2007).

La céramica de pasta blanca se mantiene muy presente en esta época en los ya mencionados centros costeros, habiendo podido observar estas piezas en superficie también en el yacimiento de Trois Îlots. Las formas principales de la CPB son grandes

24 Gran parte de esta información se encuentra recogida en la tesis inédita de Kellaf, R. La protection des biens culturels sous-marins en Algérie, cas de la région de Cherchell. Thèse de doctorat en Sciences, spécialité Archéologie, Conservation et Restauration. Université Alger 2, Institut d'Archéologie (2016). Vaya mi más sincero agradecimiento al profesor Khellaf por su excepcional acogida y las interesantes discusiones y visitas a muchos de estos yacimientos. barreños de diámetro circular u oval de las formas Uzita 2 y 3, presentes en Argel, Cherchel (Leveau, 1984: 462, fig. 248) y Tipasa (Bouchenaki, 1975: fig. 91.m237), así como cuencos y jarras de grandes dimensiones, a menudo con el borde trilobulado (Bouchenaki, 1975: 129, fig. 91.m157 y м162), y morteros. Algunas pequeñas jarras con acanaladuras muy marcadas en el cuerpo y producidas en la misma pasta perduran hasta por lo menos el s. vi d. C., como pone en evidencia un ejemplar que formaba parte del ajuar de una tumba de la necrópolis tardía de Sahet echouhada.

Sin embargo, el grupo principal en los contextos tardíos está formado por una producción destinada a ir al fuego que podríamos denominar cerámica de cocina de Mauretania Caesariensis -CMC-. Bajo esta definición se engloban una serie de piezas de cerámica de cocina-cazuelas, platos de horno, hervidores-, en cuya pasta también se fabrican cerámicas comunes -morteros-e incluso de mesa -imitaciones del tipo Hayes 8в en su variante tardía, con un borde muy puntiagudo-. La pasta posee un color entre el rojo ladrillo y el marón oscuro, y contiene esquistos y cuarzo anguloso. Es rugosa al tacto, de fractura irregular y no presenta engobe, si bien las formas finas como los boles parece haber tenido un tratamiento superficial con una arcilla más diluida. Dos fragmentos dibujados y fotografiados in situ en Tipasa, una cazuela y una tapadera, permiten observar con mayor detalle estas características (Fig. 6, n. ${ }^{\circ} 1$ y 2). El repertorio de la CMC reproduce formas clásicas de la cerámica de cocina africana, tanto de la categoría A como de la CA, como los tipos Hayes 23в, 181, 182, 196, 197 o el hervidor Uzita 48.1, si bien todos ellos con carenas muy marcadas (Fig. 6, n.o 3). Muy abundante en los yacimientos costeros situados entre Cherchel y Argel, la forma más frecuente son las tapaderas (Cherchel: Leveau, 1984: 462, fig. 248; Tipasa: Bouchenaki, 1975: fig. 91.M237). Estas tienen forma de tayín, con una prehensión cilíndrica y el cuerpo a menudo acanalado. Los bordes presentan una enorme variedad, ya sea con el labio plano, inclinado, redondeado, cuadrangular... (Fig. 6, n. ${ }^{\text {s }} 4-11$ ). 

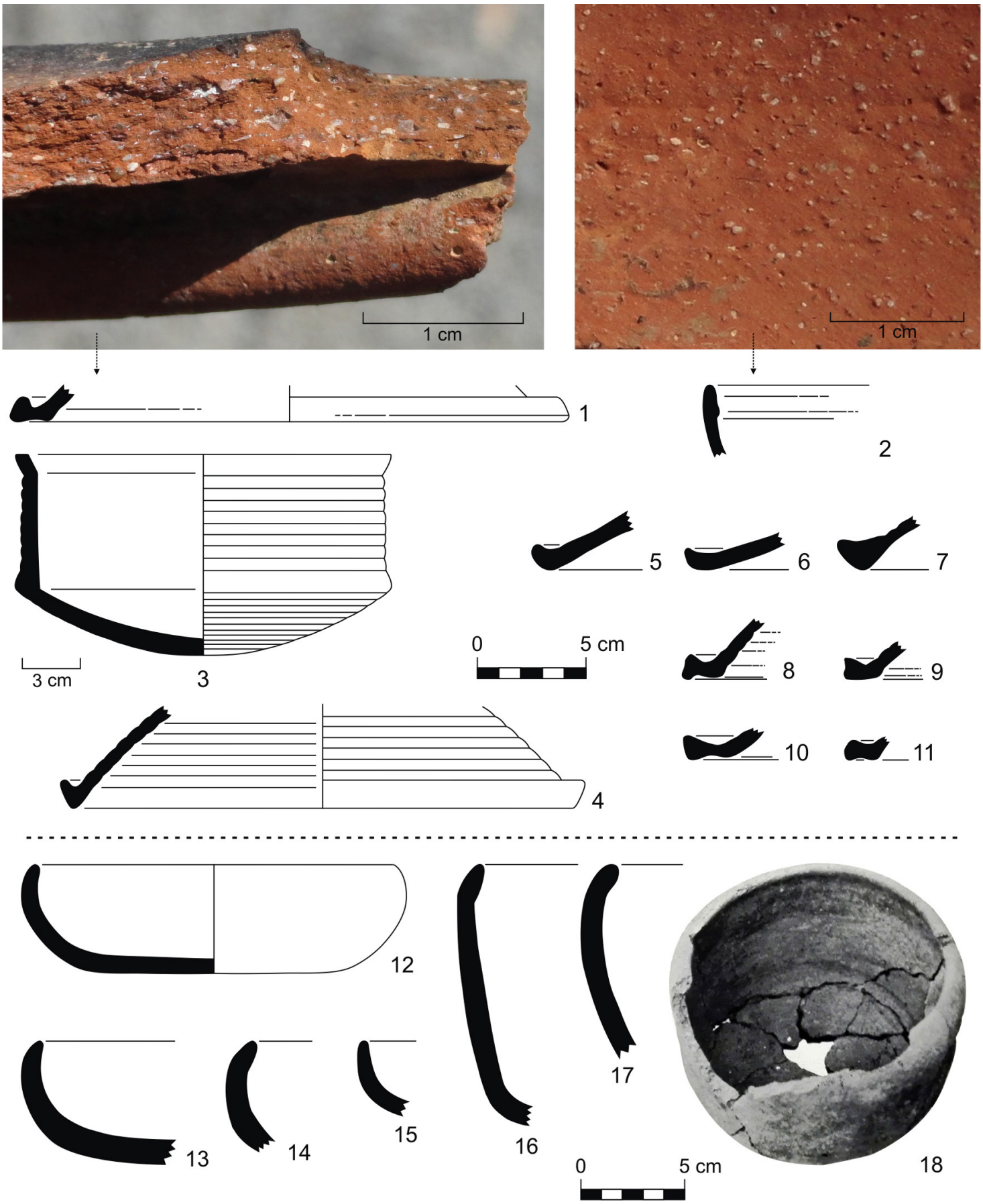

FIG. 6. Cerámica de cocina de Mauretania Caesariensis (CMC): 1-2) detalles de la pasta de una tapadera y un borde de cazuela Hayes 23B de Tipasa; 3) cazuela imitación Hayes 197 de la necrópolis de Draria-el-Achour (Camps, 1955: fig. 6, n. ${ }^{\circ}$ 5; el dibujo podría ser inexacto ya que el borde parece demasiado rectilineo y la pared muy gruesa); 4-11) tapaderas (4 = Tipasa, Bouchenaki, 1975, fig. 64.M25; 5-11= Leveau, 1984: fig. 248); 12-18) platos de cocina y ollas en cerámica modelada de Tipasa (12 = Bouchenaki, 1975: fig. 90.M133/146; los siguientes a partir de: Manacorda, 1989: $13=$ fig. 90.M143, $14=$ fig. 90.M145, 15 = fig. 90.M138, 16 = fig. $89 \cdot$ M173, $17=$ fig. $89 \cdot$ M167, $18=$ tav. XXV, 3). 
Las primeras formas de la CMC parecen atestiguarse en el s. III d. C. (Lancel, 1970: 210), si bien está plenamente documentada en los s. IV-v d. C. Un ejemplar de la Tumba Al de la necrópolis de Draria-el-Achour apareció junto con una jarra de cerámica común y tres platos tipo Hayes $61 \mathrm{~A} / \mathrm{B}$ fechados en el s. v d. C. (Camps, 1955: 235-236 y 244 , fig. 5 , n. ${ }^{\text {os }} 1,2,5$ y fig. 6, n. ${ }^{\text {os }} 5,7$ y 9A 1 ). La producción podría perdurar aún más, puesto que se han documentado varias formas en un vertedero de Cherchel fechado en los ss. $\mathrm{V}-\mathrm{VI}^{25}$. A pesar de la abundancia de estas piezas en Argel -donde algunas cerámicas medievales parecen estar realizadas en las mismas pastas-, por ahora no hay datos que permitan vincular con seguridad su producción a esta ciudad.

Por último, la tercera categoría más importante documentada en época tardía es la de las cerámicas de cocina modeladas, muy presentes en los contextos cerámicos a partir del s. IV (Manacorda, 1989: 165-167). Se trata de un grupo destinado a ir al fuego, caracterizado por una pasta de grano grueso, que se rompe fácilmente, rica en cuarzo y mica y a menudo quemada al exterior. El tipo principal es un plato/fuente de grandes dimensiones y paredes rectas que recuerda a la forma Hayes 181, acaso para cocer tortas o pan, dada su escasa altura (Fig. 6, n. $\left.{ }^{\text {ss }} 12-15\right)$. Esta forma está bien representada en Nador (Manacorda, 1989: fig. 37.68), Tipasa (Lancel, 1970: 209, fig. 61, n. ${ }^{\text {os }}$ 1-3; Bouchenaki, 1975: fig. 90) y Argel. En esta última localidad se registran también marmitas de cuerpo globular y fondo plano, con el borde entrante, dotadas de pequeños mamelones con digitaciones en la pared. La forma predominante en Nador y Tipasa posee paredes más rectilíneas (Fig. 6, n. ${ }^{\text {s }}$ 16-18). Esto invita a pensar en la existencia de distintos centros productores en la región, a diferencia de lo que sucede con otras producciones comunes y culinarias más estandarizadas como las СРв y las $\mathrm{CMC}^{26}$.

25 Abbaci y Souq, op. cit., n. 5.

26 En Argel se identifica asimismo una producción modelada hecha en una pasta muy similar a la de la CMC.

\section{Consideraciones finales}

Mediante el estudio de la evidencia cerámica, este trabajo intenta aportar nuevos elementos de lectura sobre los flujos comerciales entre el oeste de Mauretania Caesariensis y el sureste de Hispania en los ss. I-v d. C. Desde su entrada en la órbita de Roma y a partir ya de los ss. I-II d. C. los principales centros costeros del territorio mauritano importaron masivamente ánforas hispanas, como denota el caso emblemático de Nador, en especial salazones y aceite béticos, pero también vino tarraconense. Posteriormente, a partir de la segunda mitad del s. II d. C., estos productos cedieron el mercado a las ánforas del África proconsular; una tendencia bien documentada en otros puntos del Mediterráneo. Entre finales de esa centuria y el s. III, la región empezó a producir sus primeras ánforas, las Dressel 30/Keay IA, destinadas probablemente a la comercialización de vino, si bien se trata de las únicas que se adscriben con seguridad a este territorio. La riqueza de instalaciones de salazón a partir de ese momento invita a pensar en la exportación de salsas de pescado y otros productos derivados de la pesca, aunque la escasez de hornos y análisis arqueométricos impide, por ahora, completar este vacío de la investigación. La transición entre el Alto Imperio y la Antigüedad Tardía brilla por la falta de datos. Entre los ss. IV-v, aunque se mantuvo la llegada de contenedores hispanos -con mayores dificultades de cuantificación que en la fase altoimperial-, el predominio entre el material anfórico parece corresponder a las importaciones del África proconsular, sin que haya apenas información sobre producciones propias, como podría ser el caso de las ánforas Keay 38 similis y Keay 24. Entre las piezas hispanas se cuentan formas tardías de la Baetica como Dressel 23, Almagro 51a-b y Almagro 51c. Se trata de un horizonte de difícil caracterización dado que varios de estos tipos, clasificados en las publicaciones como lusitanos, pueden proceder en realidad de áreas muy dinámicas y cada vez mejor conocidas como Málaga y su entorno. Destaca asimismo la presencia de ánforas de los talleres de la costa de Cartagena -El Mojón, Mazarrón, Águilas-, tipos 
Mojón IA y pequeños spatheia, vinculados al comercio de las salazones y sus derivados entre los ss. IV-v d. C. A su vez, cabe señalar el importante desarrollo de ciertas producciones tardías de cerámica regional, como la cerámica de cocina de Mauretania Caesariensis y las cerámicas modeladas. Las CMC, al igual que sucede con la срв desde época altoimperial, ponen en evidencia la existencia de estrechas relaciones entre algunas de las principales ciudades mauritanas-Caesarea, Tipasa, Icosium-, que parecen compartir mercados y prácticas comunes. En cuanto a las lucernas, el foco productor de los tipos Bussière E IV y E V se concentró en el entorno de Cherchel y Tipasa, probablemente en esta última ciudad.

El alcance de estas reflexiones es sin duda limitado debido al desarrollo actual de los estudios. A diferencia de lo sucedido en otras regiones africanas como la Proconsular, la Mauretania Caesariensis ha conocido escasos avances, manteniendo vigentes 30 años después las palabras de Manacorda (1989: 128):

... La cultura materiale degli insediamenti romani dell'Africa settentrionale, e della Mauretania in particolare, è ancora poco analizzata; una documentazione relativamente ricca potrà rivelarsi uno strumento utile $[\ldots]$.

Aunque la provincia fuese célebre por la exportación de bienes que no han perdurado en el registro arqueológico, es evidente que la ausencia de ánforas propias en un territorio tan fértil, de más de $2000 \mathrm{~km}$ de costa, resulta a día de hoy una anomalía respecto a otras regiones del Imperio. A falta de una mejor caracterización aqueométrica de los productos mauritanos, es difícil trazar su comercialización -e identificar junto a qué otras mercancías viajaban-, salvo en casos puntuales como el de algunas lucernas o las ánforas Keay IA selladas. A ello cabe añadir la falta de datos sobre el papel que hubo de jugar un puerto de primer orden en el Mediterráneo como el de Iol/ Cesarea, en especial como hub de redistribución de mercancías -sobre todo africanas e hispanas-.

Una de las preguntas que cabría hacerse es si la búsqueda de dinámicas específicas entre la Mauretania Caesariensis y la Península Ibérica responde a una realidad comercial o se basa simplemente en el hecho de su proximidad física. El limitado número de contextos de consumo en ambas orillas, ya sean urbanos o rurales, y los mencionados problemas de cuantificación no permiten una respuesta concluyente. Sin embargo, la existencia de productos modestos que parecen quedar fuera de las grandes rutas anonarias -su distribución en Roma es escasa o nula- y que circulan entre el litoral mauritano y el Sureste hispano así parecen atestiguarlo. Sería el caso de los vasitos de paredes finas de la zona de Cartagena hallados en Argelia y de las lucernas Bussière E IV y E V encontradas en varios puntos de la costa de Hispania.

El panorama actual se encuentra en una fase de cambio gracias a las nuevas intervenciones que se desarrollan desde el CNRA y las universidades argelinas, en distintos casos mediante colaboraciones con otras instituciones internacionales. El Sureste hispano, por su proximidad geográfica y los vínculos históricos con la otra orilla, constituye un territorio privilegiado para el estudio de las relaciones comerciales con Argelia. A partir de secuencias estratigráficas cerradas es posible comenzar a caracterizar y precisar la datación de ciertas categorías cerámicas, al igual que sucediera con la sigillata africana, estudiada principalmente en los centros de consumo y no de producción. Solo mediante la publicación de nuevos datos, la revisión de los ya conocidos, la introducción de análisis arqueométricos -que deben hacerse extensivos a todas las categorías cerámicas, no solo a las ánforas o a la vajilla de mesa- y el desarrollo de la arqueología subacuática se podrá profundizar en el conocimiento de los intercambios regionales e interprovinciales en este importante sector del Occidente mediterráneo. Intercambios que no solo han de ser analizados en sentido s-N, también poniendo el acento en las conexiones E-O entre la Caesariensis y el resto de provincias africanas.

\section{Fuentes antiguas}

Anónimo: Expositio totius mundi et Gentium. Introducción, texto crítico, traducción, notas y comentario de J. Rougé (1966). Paris: Les Éditions du Cerf. 
Plinio el Viejo: Historia Natural. Introducción, traducción y notas de J. Cantó, I. Gómez Santamaría, S. González Marín y E. TARriño (2002). Madrid: Cátedra.

\section{Bibliografía}

Amraoui, T. (2014): "La production urbaine de salaisons en Algérie à l'époque romaine: l'exemple de Tipasa (Maurétanie Césarienne)". En Bотте, E y Leitch, V. (eds.): Fish and Ships. Production et commerce des salsamenta durant l'Antiquité. Actes de l'atelier doctoral (Rome, 2012). вiAma, 17, pp. 91-101.

Amraoui, T. (2017): L'artisanat dans les cités antiques de l'Algérie ( ${ }^{e r}$ siècle avant notre ère - VII' siècle après notre ìre). Archaeopress Roman Archaeology, 26. Oxford.

Anselmino, L.; Bouchenaki, M.; Carandini, A.; Leveau, Ph.; Manacorda, D.; Pavolini, C.; Pucci, G. y Salama, P. (1989): Il castellum del Nador. Storia di una fattoria tra Tipasa e Cesarea (I-VI sec. d. C.). Monografie di Archeologia Lybica, 23. Roma: "L'Erma" di Bretschneider.

BARADEZ, J. (1961): "Nouvelles fouilles à Tipasa", Lybica. Archéologie-Épigraphie, 9, pp. 7-199.

Baradez, J. (1969): "Nécropole orientale côtière de Tipasa de Maurétanie", Antiquités Africaines, 3, pp. 83-113.

Belacheheb, B. (2007): "Cruche". En Аккав, M. T. y Cheniti, M. E. B. (eds.): D’Ikosim à El Djazaïr. Catalogue de l'exposition. Argel: Musée del Antiquités, Ministère de la Culture, pp. 103.

Benseddik, N. y Potter, T. W. (1993): Fouilles du forum de Cherchell (1977-1981). Bulletin d'Archéologie Algérienne Suppl. 6. Alger.

Bernal, D.; Raissouni, B.; Ramos, J.; Zouak, M. y Parodi, M. J. (eds.) (2008): En la orilla africana del Círculo del Estrecho. Historiografía y proyectos actuales (Actas II Seminario Hispano-Marroqui de Especialización en Arqueología). Cádiz: UCA.

Bernard, G. (2018): Nec plus Ultra. L'extrême occident méditerranéen dans l'espace politique romain (218 av. J.-C.-305 apr. J.-C.). Bibliothèque de la Casa de Velázquez, 72. Madrid.

Berrocal, M. C. (2012): "Producciones anfóricas en la costa meridional de Carthago Spartaria". En Bernal, D. y Ribera, A. (eds.): Cerámicas hispanorromanas II. Producciones regionales. Cádiz: UCA, pp. 255-277.

Bonifay, M. (2004): Études sur la céramique romaine tardive d'Afrique. BAR Intern. Ser., 1301. Oxford: Archaeopress.

(C) Universidad de Salamanca
Bonifay, M. (2013): “Africa: patterns of consumption in coastal regions versus inland regions. The ceramic evidence (300-700 AD)". En Lavan, L. (ed.): Local Economies? Production and Exchange of Inland Regions in Late Antiquity. Late Antique Archaeology, 10. Leiden, pp. 529-556.

Bonifay, M. (2016): "Annexe 1. Éléments de typologie des céramiques de l'Afrique romaine". En Malfitana, D. y BONIFAY, M. (eds.): La ceramica africana nella Sicila romana/La céramique africaine dans la Sicile romaine. Monografie dell'Istituto per i Beni Archeologici e Monumentali, CNR, 12. Catania, pp. 507-573.

Bonifay, M. y Malfitana, D. (2016): "L'apport de la documentation sicilienne à l'étude du commerce de l'Afrique romaine". En Malfitana, D. y Bonifay, M. (eds.): La ceramica africana nella Sicila romana/La céramique africaine dans la Sicile romaine. Monografie dell'Istituto per i Beni Archeologici e Monumentali, CNR, 12. Catania, pp. 403-444.

Bonifay, M. y Tchernia, A. (2012): "Les réseaux de la céramique africaine (rer-ve siècles)". En KeAY, S. J. (ed.): Rome, Portus and the Mediterranean. Archaeological Monographs of the BSR, 21. London, pp. 315-336.

Bonifay, M. y Tréglia, J.-C. (2010): De Vigo à Voitenki, en passant par Pise et Parme. En Menchelli, S.; Santoro, S.; Pasquinucci, M. y Guiducci, G. (eds.): LRCW3. Late Roman Coarse Wares, Cooking Wares and Amphorae in the Mediterranean. Archaeology and Archaeometry. Comparison between western and eastern Mediterranean. BAR Intern. Ser., 2185 (II). Oxford: Archaeopress, pp. 1033-1039.

Bouchenaki, M. (1975): Fouilles de la nécropole occidentale de Tipasa (Matarès): (1968-1972). Alger: Société National d'Édition et de Diffusion.

Bussière, J. (2000): Lampes antiques d'Algérie. Monographies Instrumentum, 16. Montagnac.

Bussière, J. (2007): Lampes tardives et lampes chrétiennes. Monographies Instrumentum, 35. Montagnac.

Camps, G. (1955): "La nécropole de Draria-el-Achour", Lybica. Archéologie-Épigraphie, 3, pp. 255-264.

Corrales, P.; Compaña, J. M.; Corrales, M. y Suárez Padilla, J. (2011): "Salsamenta Malacitano. Avances de un proyecto de investigación”, Itálica, 1, pp. 29-49.

Dorbane, M. (1998): "Revision des marques de potiers des terres sigillées du Musée National des Antiquités", Annales du Musée des Antiquités, 7, pp. 25-55.

Dovis-Vicente, C. (2001): Étude du commerce maritime au IV siècle : cas de l'épave de la Luque B. Villeneuved'Ascq: Presses Universitaires du Septentrion. 
Gozalbes, E. (1993): "Observaciones acerca del comercio de época romana entre Hispania y África”, Antiquités Africaines, 29, pp. 163-176.

Gsell, S. (1911): Atlas archéologique de l'Algérie. AlgerParis.

GuÉry, R. (1970): "Notes de céramique (deuxième série): IV, deux noveaux vases décorés de la nécropole de Sétif; v, une reproduction monétaire de Théodose II sur des lampes tardives; VI, la terre sigillée claire D de Rusguniae (Tamedfoust)", Bulletin d'Archéologie Algérienne, 4, pp. 167-295.

GuÉRY, R. (1979): "Les marques de potiers sur terra sigillata découvertes en Algérie. I. Sigillées provinciales (hispanique et gallo-romaine)", Antiquités Africaines, 13, pp. 23-97.

GuÉRY, R. (1987): “Les marques de potiers sur terra sigillata découvertes en Algérie. II. Sigillée tardo-italique", Antiquités Africaines, 23, pp. 149-191.

Guéry, R. (1992): "Les marques de potiers sur terra sigillata découvertes en Algérie. IV. Sigillée italique", Antiquités Africaines, 28, pp. 15-131.

Hayes, J. W. (1972): Late Roman Pottery. Rome: BSR.

Kouici, N. (2002): "Los contactos entre la península Ibérica y el Norte de África según los datos histórico-arqueológicos de época púnico-romana”, $S P A L, 11$, pp. 277-296.

LANCEL, S. (1968): “Tipasitana III: La nécropole préromaine occidentale de Tipasa. Rapport préliminaire (campagnes de 1966 et 1967)", Bulletin d'Archéologie Algérienne, 3, pp. 85-166.

LANCEL, S. (1970): "Tipasitana IV: La nécropole romaine occidentale de la Porte de Césarée: Rapport préliminaire", Bulletin d'Archéologie Algérienne, 4, pp. 149-266.

Lancel, S. (2003): L'Algérie antique. De Massinissa à Saint Augustin. Paris: Édit. Mengès.

Landes, Ch. (2014): "De Carthage à Mina au Musée d'Archéologie Nationale", Archéologia, 519, pp. 16-17.

Laporte, J.-P. (1976-1978): "Les amphores de Tubusuctu et l'huile de Maurétanie césarienne", BACTH, $\mathrm{n}$. s., B., 12-14, pp. 131-157.

Laporte, J.-P. (2010): "Les amphores de Tubusuctu et de Saldae (Ostia v = Keay IA): une mise au point”. En Blázquez, J. M. y Remesal, J. (eds.): Estudios sobre el Monte Testaccio. Instrumenta, 35. Barcelona, pp. 601-625.

Laporte, J.-P. (2011): "Particularités de la province de Maurétanie Césarienne (Algérie centrale et occidentale)". En Briand-Ponsart, C. y ModéRAN, Y. (eds.): Provinces et identités provinciales dans l'Afrique romaine. Publications du Crahm. Caen, pp. $111-150$.
Le Glay, M. (1968): “À la recherche d'Icosium”, Antiquités Africaines, 2, pp. 7-54.

Leveau, Ph. (1977): "Les hypogées de la rive gauche de l'oued Nsara et la nécropole orientale de Caesarea (Cherchel) d'après des fouilles et des dessins anciens”, Antiquités Africaines, 11, pp. 209-256.

Leveau, Ph. (1983): "Recherches sur les nécropoles occidentales de Cherchell (Caesarea Mauretaniae). 18801961", Antiquités Africaines, 35, pp. 85-173.

Leveau, Ph. (1984): Caesarea de Maurétanie. Une ville romaine et ses campagnes. Collection de l'École Française de Rome, 70. Roma.

Leveau, Ph. (1999): "Fouilles sur la nécropole de la gare routière de Cherchell, Algérie (1992-1993)", Antiquités Africaines, 19, pp. 77-114.

Manacorda, D. (1989): "I materiali". En Anselmino L.; Bouchenaki, M.; Carandini, A.; Leveau, Ph.; Manacorda, D.; Pavolini, C.; Pucci, G. y SalaMA, P. (eds.): Il castellum del Nador. Storia di una fattoria tra Tipasa e Cesarea (I-VI sec. d. C.). Monografie di Archeologia Lybica, 23. Roma: L'Erma di Bretschneider, pp. 127-216.

Mansouri, K. (2002): "Édifices publics et évergétisme en Maurétanie Césarienne sous le Haut-Empire: témoignages épigraphiques". En Khanoussi, M.; Ruggeri, P. y Vismara, C. (eds.): L'Africa Romana, XV. Ai confini dell'impero: contatti, scambi, conflitti. Roma: Carocci Editore, pp. 1385-1414.

Panella, C. (1993): "Merci e scambi nel mediterraneo tardoantico”. En Carandini, A.; Gracco Ruggini, L. y Giardina, A. (eds.): Storia di Roma III: L'età tardoantica. Torino: Einaudi, pp. 613-697.

Panella, C. (2001): "Le anfore di età imperiale nel Mediterraneo occidentale”. En LÉvÊQue, P. y Morel, J.-P. (eds.): Céramiques héllenistiques et romaines, 3. Presses Universitaires Franc-Comtoises, pp. 177-275.

Quevedo, A. (2015): Contextos cerámicos y transformaciones urbanas en Carthago Nova (ss. II-III d. C.). Roman and Late Antique Mediterranean Pottery, 7. Oxford.

RAMON, J. (2006): "Les àmfores altimperials d'Ebusus”. En López Mullor, A. y Aquilué, X. (eds.): La producció i el comerç de les àmfores de la Provincia Hispania Tarraconensis: homenatge a Ricard Pascual $i$ Guasch. Monografies del Museu d'Arqueologia de Catalunya, 8. pp. 241-270. Barcelona.

Ramon, J. (2008): "El comercio púnico en Occidente en época tardorrepublicana (siglos -II/-I). Una perspectiva actual según el tráfico de productos envasados en ánforas". En Uroz, J.; CoArelli, F. y Noguera, J. M. (eds.): Iberia e Italia: modelos romanos de integración territorial. Murcia: Tabularium. 
Reynolds, P. (1995): Trade in the Western Mediterranean $A D$ 400-700: the ceramic evidence. BAR Intern. Ser., 604. Oxford: Tempus Reparatum.

Reynolds, P. (2010): Hispania and the Roman Mediterranean $A D$ 100-700: ceramics and trade. London: Duckworth.

Rizzo, G. (2014): "Le anfore dell'area NE”. En PANeLLA, C. y Rizzo, G. (eds.): Ostia VI. Le terme del nuotatore. I saggi nell'area NE. Le anfore, Ostia e i commerci mediterranei. Studi Miscellanei, 38. Roma, pp. 65-481.
Salama, P. (2006): "Sites commerciaux antiques sur le littoral de l'Algérois", Mélanges de l'École Française de Rome-Antiquité, 118 (2), pp. 527-547.

Tendero, M. y Ronda, A. M. (2014): "Nuevos datos sobre la Colonia Iulia Ilici Augusta (ss. II-IV d. C.)". En Ramallo, S. F. y Quevedo, A. (eds.): Las ciudades de la Tarraconense oriental entre los ss. II-IV d. C. Evolución urbanistica y contextos materiales. Murcia: Editum, pp. 275-320.

Yorke, R. A. y Davidson, D. P. (1969): "Roman harbours of Algeria”, Underwater Association Report, pp. 8-21. 
